\title{
A Retrospective Study on Ventriculoperitoneal Shunt Complications in a Tertiary Care Centre
}

\author{
Pankaj Kumar ${ }^{1} \quad$ Sharad Pandey ${ }^{1, *} \quad$ Nitin Bhakal ${ }^{1} \quad$ Sourabh Shrivastava ${ }^{1}$ \\ L. N. Gupta' Ravi Prakash Jha² \\ ${ }^{1}$ Department of Neuro Surgery, Atal Bihari Vajpyee Institute of Medical \\ Address for correspondence Sharad Pandey, MS, MCh, \\ Sciences and Dr Ram Manohar Lohia Hospital, New Delhi, India \\ 2Department of Community Medicine, Division of Biostatistics, \\ Dr Baba Sahib Ambedkar Medical College, Delhi, India \\ Department of Neuro Surgery, Atal Bihari Vajpyee Institute \\ of Medical Sciences and Dr Ram Manohar Lohia Hospital, \\ New Delhi110001, India (e-mail: drsharad23@yahoo.com).
}

Indian J Neurosurg:2020;9:170-174

\begin{abstract}
Keywords

- ventriculoperitoneal shunt

- hydrocephalus

- complications

Background Ventriculoperitoneal shunt (VPS) is a common technique employed to treat the second most common congenital brain malformation, "hydrocephalus." Postshunt insertion, the consequent complications and factors contributing to shunt malfunction are much fought occurrences. The current study was planned to assess the effectiveness of the procedure, analyze the complications of VP shunt, and recognize the factors influencing shunt malfunction.

Materials and Methods The present study was a retrospective observational study, which was conducted at the Department of Neurosurgery, PGIMER RML Hospital, New Delhi, from August 2016 to July 2018. Patients with hydrocephalus requiring shunt intervention were included in the study. A Chhabra "slit $n$ spring" hydrocephalus shunt system was inserted in all patients. All patients with VP shunts were followed to assess for any postshunt complications.

Results Out of 541 patients for whom VP shunt was inserted over a period of 2 years, 126 (23.3\%) patients developed complications. The most common cause of hydrocephalus for which VP shunt was done was tubercular meningitis $(39.3 \%, n=63)$, followed by ventriculitis $(12.38 \%, n=20)$, congenital hydrocephalus $(8.87 \%, n=14)$ and aqueductal stenosis $(5.54 \%, n=03)$. The most common complication in our study was obstruction of proximal end of the catheter by debris, which was noted in 50 patients (39.68\%). The second most common complication was poor peritoneal absorption or obstruction of lower end $(21.43 \%, n=27$ cases). Abscess along the shunt was seen in 21 patients (16.67\%). Complications were mostly documented in cases with hydrocephalus due to tubercular meningitis (TBM) (39.3\%, 63 patients) and ventriculitis (12.38\%, 20 patients). Other complications were hyperemia with superficial ulceration or complete exposure of skin overlying the tube $(11.9 \%, n=15)$, overdrainage of the ventricles leading to chronic subdural hematoma $(n=14,11.11 \%)$, and infection around the distal catheter $(4.76 \%, n=6)$.

Conclusion VPS procedure led to a complication in several patients, with the most common being obstruction of proximal catheter and poor peritoneal absorption or obstruction of lower end followed by abscess and infection.
\end{abstract}

*Previously with Department of Neuro Surgery, Sir Sunder Lal Hospital, IMS, BHU, Varanasi, Uttar Pradesh 221005, India.

Dol https://doi.org/ 10.1055/s-0040-1713562 ISSN 2277-954X.
(C) 2020. Neurological Surgeons' Society of India.

This is an open access article published by Thieme under the terms of the Creative Commons Attribution-NonDerivative-NonCommercial-License, permitting copying and reproduction so long as the original work is given appropriate credit. Contents may not be used for commercial purposes, or adapted, remixed, transformed or built upon. (https://creativecommons.org/licenses/by-nc-nd/4.0/)

Thieme Medical and Scientific Publishers Pvt. Ltd., A-12, 2nd Floor, Sector 2, Noida-201301 UP, India 


\section{Introduction}

Hydrocephalus is an excess of cerebrospinal fluid (CSF) in the ventricular system due to the imbalance between formation and absorption of CSF, which is referred to (1) obstruction of the CSF pathways, (2) overproduction of CSF, and (3) impaired venous drainage. ${ }^{1}$ Also, hydrocephalus is the second most common congenital brain malformation. ${ }^{2}$ To date, the standard treatment of hydrocephalus is ventriculoperitoneal shunt (VPS). The technique of using the peritoneal cavity for CSF absorption in VPS was developed by Kausch in $1908 .^{3}$ Although VPS insertion is a common neurosurgical procedure, complication rates in adults are poorly established, with studies reporting from 17 to $33 \%^{2,4-10}$ In a study by Yvonne et al, children demonstrated a higher rate of shunt complications than adults at 5 years ( 48 vs. $27 \%$, $p<0.0001) .{ }^{11}$ The advent of endoscopic third ventriculostomy has gained popularity due to the high-complication and failure rates of VPS. ${ }^{12}$ The major disadvantage of VPS is the fact that it constitutes a foreign body and is prone to complications like mechanical blockage, shunt infection, shunt migration and, rarely, shunt protrusion. ${ }^{13}$ If a shunt system fails to be operated correctly, the patient's life and cognitive functions are at risk; thus, necessitating the need for an urgent revision. ${ }^{14} \mathrm{~A}$ lot of research is ongoing on shunt complications which still remains a common problem..$^{15}$ The aim of this study was to assess the effectiveness of VP shunt insertion procedure against proven standards of care, in order to study complications of VP shunt and study factors influencing shunt malfunction.

\section{Materials and Methods}

The present study was a retrospective observational study conducted in the Department of Neurosurgery, PGIMER RML Hospital, New Delhi, for a period of 2 years from August 2016 to July 2018. A complete clinical assessment including a detailed history and examination with a particular emphasis on neurological examination was done for all patients after admission. A Chhabra "slit n spring" hydrocephalus shunt system was used for all patients. Patients with VP shunt complications operated at RML Hospital during the study period were included in the study. The investigations performed for all patients were complete blood count $(\mathrm{CBC})$, erythrocyte sedimentation rate (ESR), complete urine analysis, X-ray chest, and head NCCT scan or MRI scan. Specific investigations such as CSF analysis, CSF culture and sensitivity, blood culture and sensitivity, urine culture and sensitivity, pus culture and sensitivity, ultrasound of abdomen, shunt series $\mathrm{X}$-rays, and MRI of the brain were also performed when indicated. A final diagnosis was made on the basis of clinical findings, and investigations and treatment of individual patients were planned accordingly.

Statistical analysis was done using SPSS 20. Demographic characteristics and clinical feature of the patients were examined according to mean \pm standard deviation (SD) and range in case of continuous variable, whereas frequency and percentage were provided in case of a qualitative variable.
A bar diagram was used to show the frequency of various shunt complications. The normality of the variable was tested by applying the one sample Kolmogorov-Smirnov test. Chi-square test was applied to check the association between the variables. Further, the Kruskal-Wallis test was employed to see whether there were any differences in the distribution of age among the categories of shunt complication. A $p$ value less than 0.05 was considered as statistically significant.

\section{Results}

This study included 541 cases over a period of 2 years, out of which 126 (23.3\%) cases developed complications. A considerable percentage $(59.9 \%)$ of the cases were males $(n=324)$ and $40.1 \%$ of the cases $(n=217)$ were females (-Table 1 ). This study included cases from all the age groups. The mean age in this study was 15.08 years (minimum age was 15 days and maximum age was 66 years). The most common cause of hydrocephalus for which VP shunt was done was tubercular meningitis (TBM) (39.3\%), followed by ventriculitis (12.38\%), congenital hydrocephalus (8.87\%) and aqueductal stenosis (5.54\%). Other causes were intracranial mass lesions like posterior fossa mass lesions (9.42\%), cerebellopontine angle (CPA) mass (3.88\%), suprasellar mass (3.88\%), ventricular mass (1.66\%), supratentorial mass (1.66\%), Dandy-Walker malformation $(0.55 \%)$, myelomeningocele (MMC) (1.66\%), normal pressure hydrocephalus (NPH) (2.21\%), postcraniotomy (2.21\%), post intraventricular hemorrhage (IVH) (1.66\%), and subarachnoid hemorrhage (SAH) (2.77\%) (- Table 2).

The documented complications were classified according to site into two categories: (i) complications related to proximal catheter and reservoir and (ii) complications related to distal catheter.

The most common complication in our study was obstruction of proximal end of the catheter by debris, which was noted in 50 patients, out of which CSF leak causing collection around the reservoir was documented in 10 cases. As many as 27 patients showed poor peritoneal absorption or obstruction of lower end, leading to distal failure and CSF collection under the skin surrounding the distal catheter. This was the second most common complication in this study.

Table 1 Distribution of various age group in patients of hydrocephalus with complications

\begin{tabular}{|l|l|l|}
\hline Age group & Males & Females \\
\hline $0-3$ mo & 37 & 29 \\
\hline $4-6$ mo & 25 & 5 \\
\hline $7-12$ mo & 42 & 26 \\
\hline $1-10 y$ & 89 & 54 \\
\hline $11-20 y$ & 42 & 44 \\
\hline $21-40 y$ & 41 & 27 \\
\hline $41-60 y$ & 45 & 32 \\
\hline$>60 y$ & 3 & 0 \\
\hline Total & 324 & 217 \\
\hline
\end{tabular}


Abscess along the shunt was seen in 21 patients and mostly at the upper end. Infection around the distal catheter was reported in 06 patients. As many as 14 patients developed over drainage of the ventricles, leading to chronic subdural hematoma ( - Fig. 1).

Table 2 Distribution of complications in patients of hydrocephalus with various etiology

\begin{tabular}{|c|c|c|c|}
\hline Causes & $\begin{array}{l}\text { No. of } \\
\text { cases }\end{array}$ & $\begin{array}{l}\% \text { of } \\
\text { cases }\end{array}$ & $\begin{array}{l}\text { Complications } \\
\text { in cases (no.) }\end{array}$ \\
\hline Aqueductal stenosis & 30 & 5.54 & 3 \\
\hline Congenital & 48 & 8.87 & 14 \\
\hline CPA mass & 21 & 3.88 & 4 \\
\hline Dandy-Walker & 3 & 0.55 & 0 \\
\hline MMC & 9 & 1.66 & 0 \\
\hline $\mathrm{NPH}$ & 12 & 2.21 & 1 \\
\hline Pineal tumor & 12 & 2.21 & 1 \\
\hline Postcraniectomy & 12 & 2.21 & 1 \\
\hline Post IVH & 9 & 1.66 & 0 \\
\hline Posterior fossa mass & 51 & 9.42 & 10 \\
\hline $\mathrm{SAH}$ & 15 & 2.77 & 1 \\
\hline Suprasellar mass & 21 & 3.88 & 8 \\
\hline Supratentorial mass & 9 & 1.66 & 0 \\
\hline TBM & 213 & 39.3 & 63 \\
\hline Ventricular mass & 9 & 1.66 & 0 \\
\hline Ventriculitis & 67 & 12.38 & 20 \\
\hline Total & 541 & 100 & $126(23.29 \%)$ \\
\hline
\end{tabular}

Abbreviations: IVH, intraventricular hemorrhage; MMC, myelomeningocele; NPH, normal pressure hydrocephalus; $\mathrm{SAH}$, subarachnoid hemorrhage; TBM, tubercular meningitis.

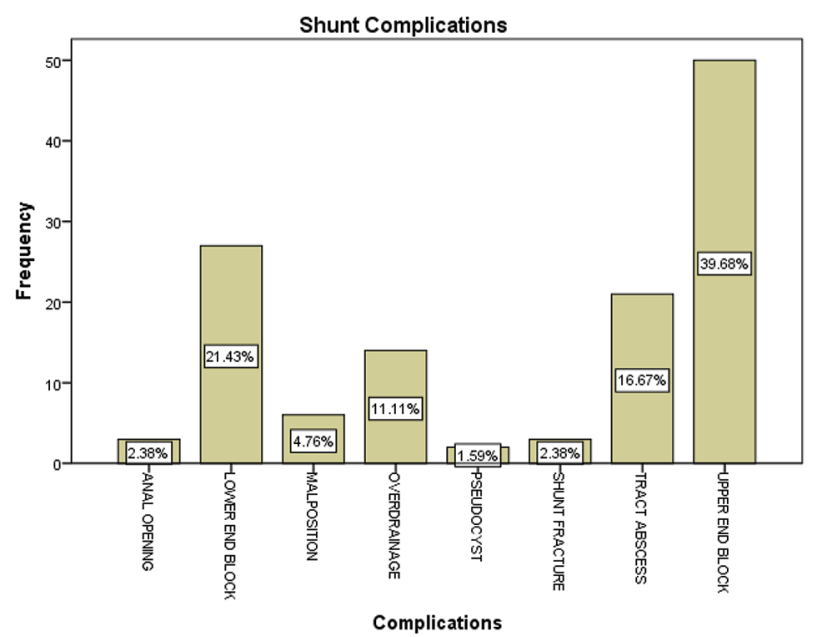

Fig. 1 Bar diagram showing the various types of complications in VP shunt treated patients of hydrocephalus. Abbreviation: VP, ventriculoperitoneal.
Fracture can also occur at any site along the course of the distal tube, especially near bony prominences. In our study, three patients developed fracture with distal tube migration. Extrusion of the distal end of distal catheter through anus was also reported in three patients. Two patients had distal failure due to obstruction of the distal end of the catheter and pseudocyst formation, causing closed narrow space for CSF drainage and VP shunt malfunctioning (- Table 3). Other complication was of malpositioning due to ventricular end getting positioned into occipital horn or brain parenchyma, as reported. The distribution of age is same across various categories of shunt complications. Independent samples Kruskal-Wallis test was applied. The $p$ value was 0.569 (statistically insignificant), which means we have to retain the null hypothesis, that is, the distribution of age is identical across various categories of shunt complication (-Fig. 2).

These complications were managed surgically. Various surgeries performed included proximal revision, distal revision, debridement, redirection of misdirected catheter, repositioning of the distal catheter, new VP shunt on the other side, changing the shunt pressure to higher one in case of chronic subdural hematoma, or closure of hernia sac. Most of the complications were documented in cases with hydrocephalus due to TBM (63 cases) and ventriculitis (20 cases).

\section{Discussion}

Although VP shunt is an effective surgical treatment modality for hydrocephalus, it is disadvantaged due to shunt-related complications. ${ }^{16}$ As maintaining normal CSF flow dynamics is a lifelong requirement, multiple surgical procedures may be required lifelong. ${ }^{17}$ In neonates, scalp necrosis is a common complication associated with repeated VP shunts due to the inherent skin fragility and the superficial nature of the shunt. ${ }^{18,19}$ Peacock and Currer found shunt blockage in $20 \%$ of their patients. ${ }^{20}$ Mwan'gombe and Omulo reported an infection rate of $24.6 \%$ among children operated for nontumor hydrocephalus in Nairobi. ${ }^{21}$ In the current study, shunt obstruction was reported in approximately $14.2 \%$ of patients (9.2\% proximal obstruction by debris and $5 \%$ distal obstruction). Infection was also reported in $3.9 \%$ of patients. Hamada and Abou Zeid reported misdirection of proximal catheter in $7.1 \%$ patients

Table 3 Types of complications in patients treated with VP shunt for hydrocephalus

\begin{tabular}{|l|l|}
\hline Type of complications & No. of cases \\
\hline Upper end blockage & 50 \\
\hline Lower end malfunction & 27 \\
\hline Abscess & 21 \\
\hline Overdrainage & 14 \\
\hline Malposition & 6 \\
\hline Distal tube migration & 3 \\
\hline Fracture & 3 \\
\hline Abdominal pseudocyst & 2 \\
\hline
\end{tabular}


Hypothesis Test Summary

\begin{tabular}{|c|c|c|c|c|}
\hline & Null Hypothesis & Test & Sig. & Decision \\
\hline 1 & $\begin{array}{l}\text { The distribution of age is } \\
\text { across categories of } \\
\text { Shunt_Complication. }\end{array}$ & $\begin{array}{c}\text { is the same lndependent- } \\
\text { Kamples } \\
\text { Kruskal- } \\
\text { injallis Test }\end{array}$ & .569 & $\begin{array}{l}\text { Retain the } \\
\text { null } \\
\text { hypothesis. }\end{array}$ \\
\hline
\end{tabular}

Asymptotic significanoes are displayed. The significanoe level is .05.

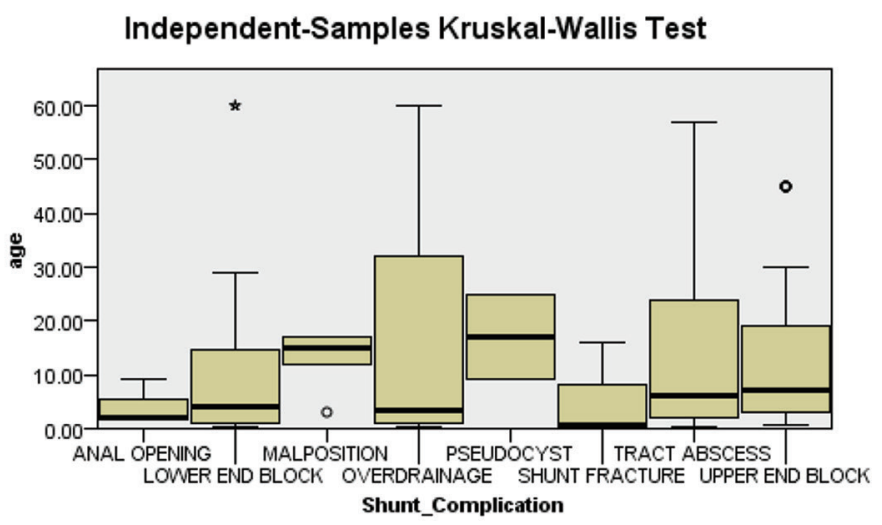

\begin{tabular}{|lr|}
\hline Total $\boldsymbol{N}$ & 126 \\
\hline Test Statistic & 5.755 \\
\hline Degrees of Freedom & 7 \\
\hline Asymptotic Sig. (2-sided test) & .569 \\
\hline
\end{tabular}

1. The test statistic is adjusted for ties.

2. Multiple comparisons are not performed because the overall test does not show significant differences across samples.

Fig. 2 Box plot showing comparison of various shunt complications with age in patients of hydrocephalus $(p=0.569)$.

of their shunt malfunction series. Aldrich and Harmann found that shunt disconnection and fracture accounted for $15 \%$ of their shunt malfunctions and that occipitally placed shunts had a higher tendency to dislocate than frontally placed shunts. ${ }^{22}$ We found comparatively lesser cases of shunt fracture, which may be due to different entry points employed for catheter placement. Abdominal complications of VP shunt are not rare and the main causes of distal catheter failure are attributed to extraperitoneal retraction of the catheter and subcutaneous or intra-abdominal CSF collections. $^{23}$ In the current study, intra-abdominal pseudocyst was reported in only two cases. In the current study, three patients reported with a VP shunt distal catheter per rectum without any complications in the form of obstruction or peritonitis. Similarly, in a study by Sathyanarayana et al, protrusion of distal catheter per anus without any complications such as obstruction or peritonitis was documented. ${ }^{24}$

Various previous studies have reported that age and principal diagnosis (etiology) to be independent contributors to the risk of initial shunt failure. ${ }^{25-27}$ In agreement with these studies, the current study demonstrated that age and etiology were significantly associated with shunt revision, where 85 (66.66\%) patients with VP shunt complications were below 10 years of age. Accordingly, there was a higher rate of complications seen in cases with TBM (50\%) and ventriculitis (15.8\%).

Out of 213 diagnosed cases of TBM who were underwent VP shunt insertion, 63 patients developed complication, which was $50 \%$ of all complications in this study. Of all the cases included in this study, 67 cases were diagnosed with ventriculitis, out of which 20 had shunt complication. 


\section{Conclusion}

Despite complications, the VP shunt remains the main surgical procedure used for hydrocephalus management. Although VP shunt insertion is a common neurosurgical procedure, it demands expertise, great care and aseptic precautions to avoid or limit complications to the minimum.

\section{Authors' Contributions}

S. P. and P. K. contributed to the report conception and design. N. B. contributed to the analysis and interpretation of data. N. B. and S. P. drafted the manuscript. L. N. G. and S. S. revised the manuscript. All authors read and approved the final manuscript.

\section{Conflict of Interest}

None declared.

\section{References}

1 Kandasamy J, Jenkinson MD, Mallucci CL. Contemporary management and recent advances in paediatric hydrocephalus. BMJ 2011;343:d4191

2 Wu Y, Green NL, Wrensch MR, Zhao S, Gupta N. Ventriculoperitoneal shunt complications in California: 1990 to 2000. Neurosurgery 2007;61(3):557-562

3 Chung JJ, Yu JS, Kim JH, Nam SJ, Kim MJ. Intraabdominal complications secondary to ventriculoperitoneal shunts: CT findings and review of the literature. Am J Roentgenol 2009;193(5):1311-1317

4 Korinek AM, Fulla-Oller L, Boch AL, Golmard JL, Hadiji B, Puybasset L. Morbidity of ventricular cerebrospinal fluid shunt surgery in adults: an 8-year study. Neurosurgery 2011;68(4) :985-994

5 Puca A, Anile C, Maira G, Rossi G. Cerebrospinal fluid shunting for hydrocephalus in the adult: factors related to shunt revision. Neurosurgery 1991;29(6):822-826

6 Khan F, Rehman A, Shamim MS, Bari ME. Factors affecting ventriculoperitoneal shunt survival in adult patients. Surg Neurol Int 2015;6:25

7 Reddy GK, Bollam P, Caldito G. Long-term outcomes of ventriculoperitoneal shunt surgery in patients with hydrocephalus. World Neurosurg 2014;81(2):404-410

8 Reddy GK. Ventriculoperitoneal shunt surgery and the incidence of shunt revision in adult patients with hemorrhagerelated hydrocephalus. Clin Neurol Neurosurg 2012;114(9): 1211-1216

9 Reddy GK, Bollam P, Caldito G. Ventriculoperitoneal shunt surgery and the risk of shunt infection in patients with hydrocephalus: long-term single institution experience. World Neurosurg 2012;78(1-2):155-163

10 O'Kelly CJ, Kulkarni AV, Austin PC, Urbach D, Wallace MC. Shunt-dependent hydrocephalus after aneurysmal subarachnoid hemorrhage: incidence, predictors, and revision rates. Clinical article. J Neurosurg 2009;111(5):1029-1035
11 Wu Y, Green NL, Wrensch MR, Zhao S, Gupta N. Ventriculoperitoneal shunt complications in California: 1990 to 2000. Neurosurgery 2007;61(3):557-562, discussion 562-563

12 Bouras T, Sgouros S. Complications of endoscopic third ventriculostomy: a systematic review. Acta Neurochir Suppl (Wien) 2012;113:149-153

13 de Ribaupierre S, Rilliet B, Vernet O, Regli L, Villemure JG. Third ventriculostomy vs ventriculoperitoneal shunt in pediatric obstructive hydrocephalus: results from a Swiss series and literature review. Childs Nerv Syst 2007;23(5):527-533

14 Ojo AO, Olumide E, Kanu OO, et al. Unusual complication of ventriculoperitoneal shunt. Romanian Neurosurg 2013;24: 375-378

15 Hussain M, Raja RA, Shaikh AU, Ali MH. Ventriculoperitoneal shunt blockage. J Ayub Med Coll Abbottabad 2012;24(3-4): $82-84$

16 Shao Y, Li M, Sun JL, et al. A laparoscopic approach to ventriculoperitoneal shunt placement with a novel fixation method for distal shunt catheter in the treatment of hydrocephalus. Minim Invasive Neurosurg 2011;54(1):44-47

17 Reddy GK. Ventriculoperitoneal shunt surgery and the incidence of shunt revision in adult patients with hemorrhagerelated hydrocephalus. Clin Neurol Neurosurg 2012;114(9): 1211-1216

18 Ammar A, Nasser M. A long-term complication of burying a shunt valve in the skull. Neurosurg Rev 1995;18(1):65-67

19 Bot GM, Ismail NJ, Usman B, et al. Subpericranial shunt valve placement: a technique in patients with friable skin. Childs Nerv Syst 2014;30(8):1431-1433

20 Peacock WJ, Currer TH. Hydrocephalus in childhood. A study of 440 cases. S Afr Med J 1984;66(9):323-324

21 Mwang'ombe NJ, Omulo T. Ventriculoperitoneal shunt surgery and shunt infections in children with non-tumour hydrocephalus at the Kenyatta National Hospital, Nairobi. East Afr Med J 2000;77(7):386-390

22 Aldrich EF, Harmann P. Disconnection as a cause of ventriculoperitoneal shunt malfunction in multicomponent shunt systems. Pediatr Neurosurg 1990-1991-1991;16(6):309-311

23 Yung S, Chan TM. Pathophysiological changes to the peritoneal membrane during PD-related peritonitis: the role of mesothelial cells. Mediators Inflamm 2012;2012:484167

24 Sathyanarayana S, Wylen EL, Baskaya MK, Nanda A. Spontaneous bowel perforation after ventriculoperitoneal shunt surgery: case report and a review of 45 cases. Surg Neurol 2000; 54(5):388-396

25 Berry JG, Hall MA, Sharma V, Goumnerova L, Slonim AD, Shah SS. A multi-institutional, 5-year analysis of initial and multiple ventricular shunt revisions in children. Neurosurgery 2008;62(2):445-453

26 Patwardhan RV, Nanda A. Implanted ventricular shunts in the United States: the billion-dollar-a-year cost of hydrocephalus treatment. Neurosurgery 2005;56(1):139-144

27 Tuli S, Drake J, Lawless J, Wigg M, Lamberti-Pasculli M. Risk factors for repeated cerebrospinal shunt failures in pediatric patients with hydrocephalus. J Neurosurg 2000;92(1):31-38 